\title{
Metabolic surgery and obstructive sleep apnoea: the protective effects of bariatric procedures
}

\author{
Hutan Ashrafian, ${ }^{1,2}$ Carel W le Roux, ${ }^{2}$ Simon P Rowland, ${ }^{1}$ Mariam Ali, \\ Andrew R Cummin, ${ }^{3}$ Ara Darzi, ${ }^{1}$ Thanos Athanasiou ${ }^{1}$
}

${ }^{1}$ The Department of Surgery and Cancer, Imperial College London, London, UK ${ }^{2}$ Section of Investigative Medicine, Division of Diabetes, Endocrinology and Metabolism Department of Medicine, Imperial College London, London, UK

${ }^{3}$ National Heart and Lung Institute, Imperial College London, London, UK

\section{Correspondence to} Hutan Ashrafian, Clinical Lecturer in Surgery and Wellcome Trust Research Fellow, Department of Surgery and Cancer, Imperial College London, 10th Floor, Queen Elizabeth the Queen Mother (QEOM) Building, Imperial College Healthcare NHS Trust at St Mary's Hospital, Praed Street, London W2 1NY, UK; h.ashrafian@imperial.ac.uk

Received 11 September 2010 Accepted 8 March 2011 Published Online First 27 June 2011

\section{ABSTRACT}

The global epidemic of obesity and the worldwide prevalence of obstructive sleep apnoea (OSA) are both increasing. Epidemiological studies reveal an association between obesity, weight gain and OSA. Metabolic or bariatric operations provide sustained weight loss and resolve or improve the symptoms of OSA in the majority of morbidly obese individuals. These operations also modulate the metabolic profile to improve glycaemic control, to decrease cardiovascular risk and obesityrelated mortality. The beneficial effects of metabolic operations on OSA include mechanical weight-dependent and metabolic weight-independent effects that are achieved through the BRAVE effects: (Bile flow alteration; Reduction of gastric size; Anatomical gut rearrangement and altered flow of nutrients; Vagal manipulation; and Enteric gut hormone modulation). These result in an improvement in insulin resistance, adipokines, cytokines and systemic inflammation. A literature analysis was performed with statistical pooling of available surgical and medical studies to determine whether the weighted mean decrease in body mass index and sleep apnoea severity (measured by the apnoea-hypopnoea index) are larger in metabolic surgical studies than in non-surgical weight loss studies (diet, exercise and medication). However, heterogeneity across available trials, poor follow-up measures and a deficiency in comparative studies between surgical and non-surgical therapy precludes definitive statements regarding the relative benefits of surgical therapy. Further research is required to quantify robustly the effects and mechanisms of sleep apnoea resolution by metabolic surgery, which may reveal novel non-surgical treatments or enhanced surgical strategies in the management of this multisystem sleep disorder.

\section{INTRODUCTION}

The global epidemic of obesity and the worldwide prevalence of sleep apnoea are both increasing. According to the WHO there are at least 300 million obese adults ${ }^{1}$ and an estimated 100 million individuals who suffer from sleep apnoea. ${ }^{2}$ Both conditions contribute to increased worldwide mortality and healthcare costs, and sleep apnoea is now considered as one of the most common organic sleep disorders. Obstructive sleep apnoea (OSA) syndrome is characterised by frequent episodes of apnoea and hypopnoea due to periods of upper airway collapse which can result in hypertension, increased cardiovascular mortality, stroke, decreased quality of life, sleepiness and morbidity associated with disordered sleep. ${ }^{3}$

The epidemiological association between obesity rates and sleep-disordered breathing has been progressively studied to identify obesity as a significant risk factor for the development of OSA. ${ }^{3}$ There are several other risk factors for sleep apnoea including sex, family history, race/ethnicity, craniofacial abnormalities, type 2 diabetes mellitus, menopause and behaviours including smoking and alcohol consumption. Several methods have been applied to reduce the burden of obesity, including disease prevention, lifestyle change, behavioural modification and pharmacotherapy. Patients have found the weight loss offered by these treatments difficult to maintain in the long term. Surgical modalities do, however, achieve longstanding weight loss in the severely obese population. The operations, initially called 'bariatric' procedures, have demonstrated a maintenance of weight loss for over 15 years ${ }^{4}$ while also providing beneficial metabolic effects that include improved glycaemic control in the majority of morbidly

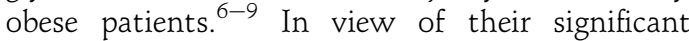
metabolic effects, these procedures are now known as 'metabolic' operations.

Longitudinal studies on metabolic surgery have revealed that successful weight loss also results in lower sleep apnoea rates. In this review we describe the effects and potential mechanisms of sleep apnoea resolution by metabolic surgery.

\section{EPIDEMIOLOGY OF OBESITY AND OSA}

OSA is present in $4-9 \%$ of adult men and $1-2 \%$ of adult women in the general population when assessed by polysomnographic criteria (apnoeahypopnoea index $(\mathrm{AHI})>5 / \mathrm{h}$ ) and the presence of sleepiness. ${ }^{10}$ Its prevalence is highest in men aged 40-65 years although it is increasingly diagnosed in all age groups of both sexes. Based on polysomnography alone, the prevalence can be as high as $17-24 \%$ in men and $5-9 \%$ in women. The data from these studies were collected in the late 1980s and early 1990s when obesity was significantly less prevalent, rendering these values as a likely underestimation of the actual prevalence of OSA in the current era. ${ }^{10-18}$

The association of obesity with sleep apnoea was first described in the Ancient Ptolemaic dynasty (305-30 BC) and was regarded in the late 19 th century as the Pickwickian syndrome. ${ }^{19} 20$ Approximately $70 \%$ of patients with sleep apnoea present with obesity, ${ }^{21}$ and $40 \%$ of patients with obesity suffer from sleep apnoea. The 'Sleep in America' survey of the National Sleep Foundation ${ }^{22}$ revealed that $57 \%$ of obese individuals are at high risk of OSA, and its incidence in morbidly obese patients can be 12-30 times higher than the incidence in the general population. ${ }^{23}$ The prevalence 
of OSA in metabolic surgical candidates with a body mass index (BMI) of $\geq 35 \mathrm{~kg} / \mathrm{m}^{2}$ may range from $60 \%$ to $83 \%{ }^{23-35}$

The Wisconsin Sleep Cohort Study prospectively demonstrated in 690 randomly selected individuals that a 10\% increase in body weight was associated with a sixfold increase in the risk of developing sleep apnoea over a 4-year period and also raised the $\mathrm{AHI}$ by $32 \%$. Conversely, it showed that a $10 \%$ weight loss was associated with a $26 \%$ decrease in AHI. In this study, an increase of $1 \mathrm{SD}$ in any measure of obesity body habitus was related to a threefold increase in the risk of an apnoea-hypopnoea score of $\geq 5 .{ }^{10}$ The Sleep Heart Health Study reported an OR of 2.4 for an AHI of $\geq 15$ with a BMI difference of $10 \mathrm{~kg} / \mathrm{m}^{2}$. It also revealed that, of the three measures of body habitus assessed, the effect size for an AHI of $\geq 15$ was greatest for BMI and was negligible for waist-to-hip ratio. ${ }^{36}$

The Cleveland Family Study reported that the 5-year incidence of sleep apnoea is approximately $7.5 \%$ where both BMI and waist-to-hip ratio are independent predictors of disease. They demonstrated that the predominance for men suffering from sleep apnoea diminished with increasing age so that, by the age of 50, the incidence between men and women was equal. ${ }^{37}$ Furthermore, the study showed that the contribution of BMI to sleep-disordered breathing was negligible after 60 years of age. ${ }^{37}$

Although the incidence of OSA is highest for middle-aged men in the general population, one prospective survey has revealed an increased female prevalence of sleep apnoea in morbidly obese surgical candidates (78\% women, $22 \%$ men). ${ }^{38}$ One study which specifically studied women undergoing bariatric surgery found the prevalence of OSA to be as high as $92.5 \%$ in this subgroup of patients. ${ }^{39}$ These changes may reflect the role of sex steroids on respiratory control and the pathogenesis of sleep apnoea. Decreased hormone levels in the menopause are associated with the development of sleep apnoea, and hormone therapy with oestrogen and progesterone replacement provides a therapeutic effect. ${ }^{40-42}$

Several anthropometric measures of body fat have been associated with the severity of sleep apnoea symptoms and polysomnographic findings. These include BMI, percentage of body fat, percentage predicted body weight, neck and abdominal circumferences, skin folds, subcutaneous fat of the neck region, parapharyngeal fat pads, subcutaneous and intra-abdominal fat. Of these, BMI has been the most widely applied measure of body fat in OSA due to its practicality and consistency of calculation in obese patients. Patients in their sixth decade and onward have a decreasing association between sleep apnoea and BMI. ${ }^{43}$ It is also recognised that obese subjects can suffer from sleepiness which is related to the systemic effects of obesity and not necessarily related to sleep apnoea.

It is now increasingly recognised that the symptoms of sleep apnoea can improve with surgical-induced weight loss. Dixon et al demonstrated independent predictors of AHI based on multivariate analysis of an OSA structured interview known by the BASHIM acronym. These included (1) BMI $\geq 45 \mathrm{~kg} / \mathrm{m}^{2}$; (2) age; (3) sleep apnoea (observed); (4) glycosylated haemoglobin (HbA1c) $\geq 6 \%$; (5) insulin $\geq 28 \mu \mathrm{mol} / 1$ (fasting plasma levels); and (6) male sex. The authors proposed a simple scoring system to predict moderate or severe OSA. A score of $\geq 3$ points with an AHI $\geq 15$ had $89 \%$ sensitivity and $81 \%$ specificity whereas a score of $\geq 3$ points with an AHI $\geq 30$ had $96 \%$ sensitivity and $71 \%$ specificity. ${ }^{44}$

\section{METABOLIC SURGERY AND REDUCTION IN OBESITY-RELATED MORTALITY}

Metabolic operations are increasingly performed worldwide, accounting for over 344000 cases each year. ${ }^{45}$ There are numerous types of operations (gastric banding, sleeve gastrectomy, biliopancreatic diversion, biliopancreatric diversion/ duodenal switch and gastric bypass) and the mechanisms by which they work are still unclear. The gastric bypass procedures consist of a number of physiological steps, the so-called BRAVE effects $^{46}$ : (1) Bile flow alteration; (2) Reduction of gastric size; (3) Anatomical gut rearrangement and altered flow of nutrients; (4) Vagal manipulation; and (5) Enteric gut hormone modulation (figure 1).

Most operations are now performed minimally invasively (using laparoscopic techniques) and a recent multicentre prospective observational study revealed an overall operative 30 -day mortality of $0.3 \%$ with a 30 -day morbidity of $4.3 \% .{ }^{47}$ These procedures provide sustained long-term weight loss, improved glycaemic control and long-term cost-effectiveness. ${ }^{48}$ Traditionally they have been applied only to patients with BMI $>35 \mathrm{~kg} / \mathrm{m}^{2}$ and obesity comorbidities (suggested by the National Institutes of Health (NIH) in the USA and the National Institute for Health and Clinical Excellence (NICE) in the UK). In view of their favourable metabolic effects, however, these procedures have been increasingly performed within study protocols in patients with BMI $<35 \mathrm{~kg} / \mathrm{m}^{2}$.

Metabolic surgery has never been subjected to a randomised controlled study for mortality benefit but, within cohort studies, an overall all-cause mortality benefit has been demonstrated when compared with non-surgical obese matched controls. ${ }^{5} 49$

\section{METABOLIC SURGERY AND OSA REDUCTION}

Metabolic surgery can significantly improve or resolve sleep apnoea in morbidly obese individuals. One large meta-analysis ${ }^{6}$ of 136 metabolic surgical studies with a total of 22094 patients reported that $19.6 \%$ of surgical candidates reporting sleepdisordered breathing. The studies that considered OSA reported on a total of 1195 patients where sleep apnoea was resolved in $85.7 \%$ (95\% CI $79.2 \%$ to $92.2 \%$ ), improved or resolved in $83.6 \%$ (95\% CI, $71.8 \%$ to $95.4 \%$ ) and corresponded to a decrease in apnoeas or hypopneas by $33.9 / \mathrm{h}$ ( $95 \%$ CI 17.5 to 50.2 ). It is unclear why the proportion of patients with disease resolution is higher than the proportion of patients with resolution or improvement after surgery. This could be a result of the heterogeneity in study outcomes, diagnosis criteria and selection for this analysis. The Swedish Obese Subjects (SOS) study commenced in 1987 and is ongoing. It is a prospective non-randomised controlled study of 4047 matched individuals

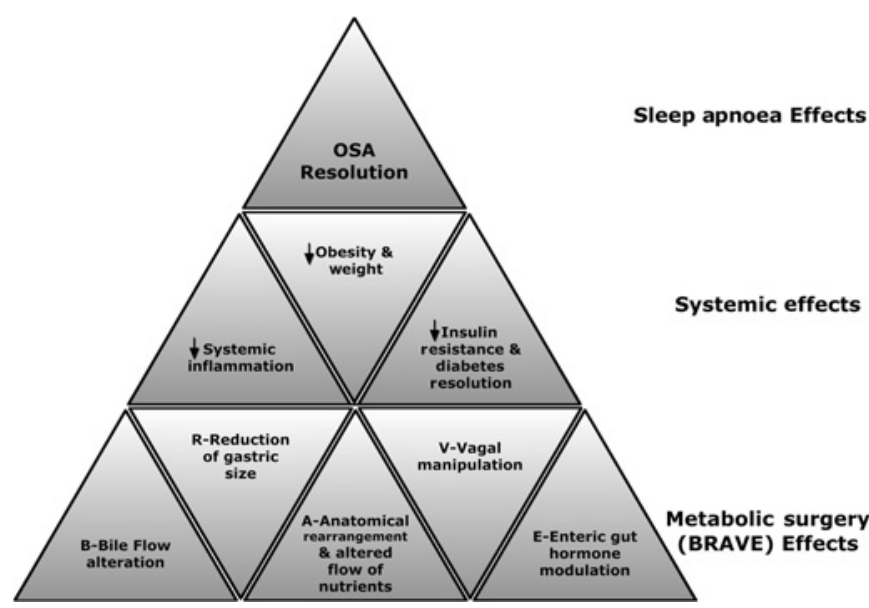

Figure 1 Mechanisms of the resolution of obstructive sleep apnoea (OSA) after metabolic surgery. 
approximately divided into two equally-sized arms: surgically treated patients and a conventional obesity treatment group. ${ }^{4}$ In their cohort, the study group identified 1592 individuals who completed 2-year follow-up sleep apnoea questionnaires used in the study. They demonstrated that, compared with a control group, postoperative patients had significantly lower symptoms of sleep apnoea and reported a significant reduction in the persistence of apnoea episodes (27.9\% vs $71.3 \%$ ) and snoring $(21.6 \%$ vs $65.5 \%) .{ }^{50}$

A recent meta-analysis ${ }^{51}$ assessing the effects of surgical weight loss on measures of OSA identified 12 studies with 342 patients in whom the pooled AHI was reduced by 38.2 events/h (95\% CI 31.9 to 44.4$)$ to a final value of 15.8 events/h $(95 \%$ CI 12.6 to 19.0$)$ based on a random effects model. The pooled BMI was reduced by $17.9 \mathrm{~kg} / \mathrm{m}^{2}$ (95\% CI 16.5 to 19.3 ) to $37.7 \mathrm{~kg} / \mathrm{m}^{2}$ (95\% CI 36.6 to 38.9 ). The inclusion criteria for this study required the reporting of both preoperative and postoperative measures of polysomnography performed in accordance with recommendations of the American Academy of Sleep Medicine. As a result, the pooled outcomes for the change in BMI and $\mathrm{AHI}$ were not derived from matching studies and the analysis for each parameter did not include all 12 studies listed, despite an unavoidable heterogeneity between them.

We calculated (table 1) the weighted mean change (random effects model) of BMI and AHI of all metabolic surgical studies to date using the databases Medline, PubMed, EMBASE and the Cochrane Library (from inception to June 2011) reporting on both these parameters (inclusion criteria for analysis). The results show that, in 359 subjects with a mean BMI of $55 \mathrm{~kg} / \mathrm{m}^{2}$, surgery offers a weighted decrease of BMI by $16 \mathrm{~kg} / \mathrm{m}^{2}(16.09$, $95 \%$ CI 13.27 to 18.92 ) and a weighted decrease of AHI by $34 / \mathrm{h}$ (34.22, 95\% CI 25.27 to 43.18) (RevMan Computer program Version 5.0, Copenhagen: The Nordic Cochrane Centre, Cochrane Collaboration, 2008). This statistical pooling analysis was only possible for a limited number of studies because data were lacking. Although there are no randomised controlled studies comparing lifestyle and surgical weight loss therapies that focus on robust sleep apnoea endpoints, both the weight loss effects of surgery (based on BMI) and the changes in AHI are greater in surgical studies (tables 1 and 2).

The limitation of the surgical studies is related to their design. The majority are non-comparative retrospective studies with

Table 1 Metabolic surgical studies reporting on weight loss and indices of sleep apnoea before and after surgery

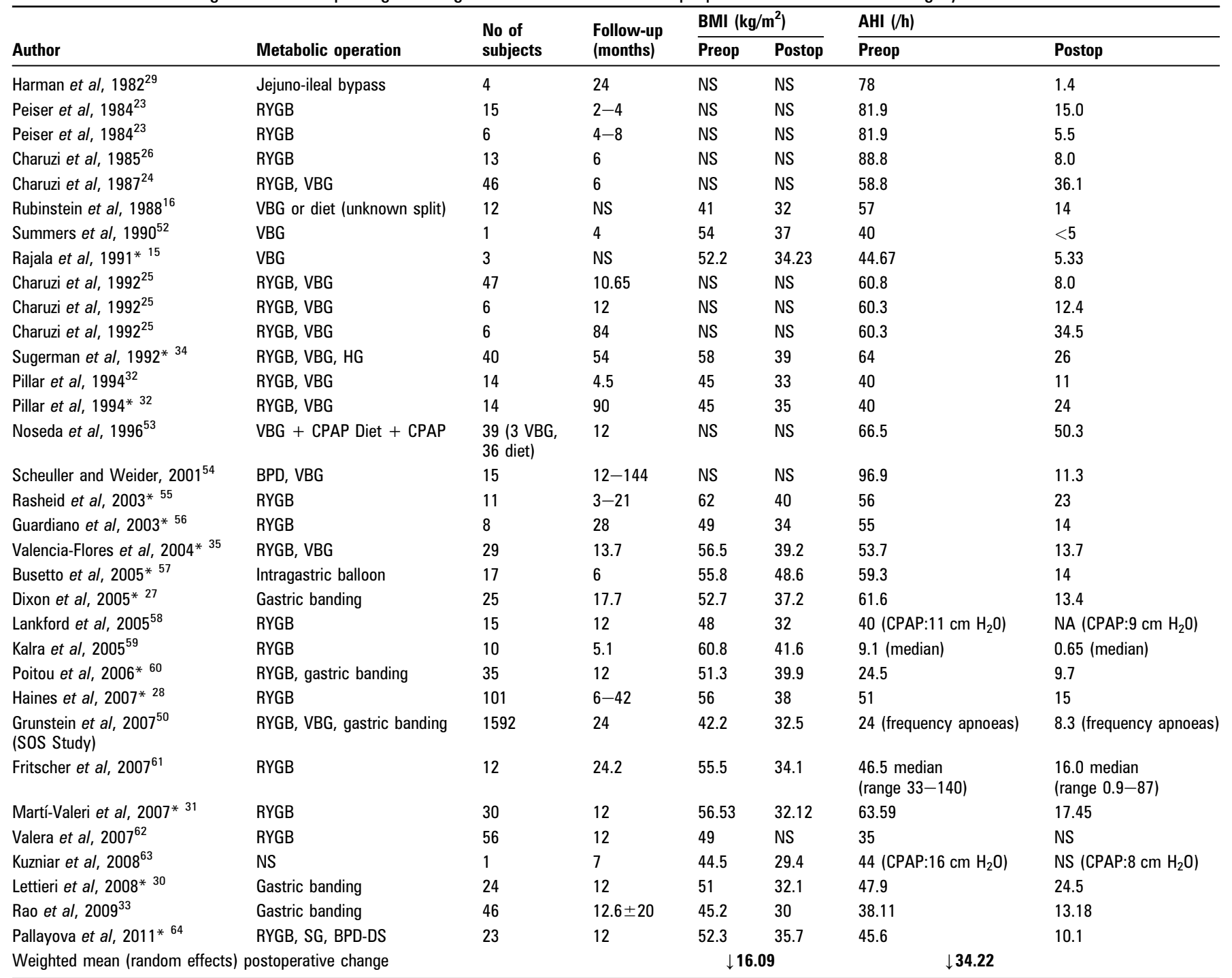

*Studies reporting the postoperative changes of both $\mathrm{BMI}$ and $\mathrm{AHI}$ which were subsequently included in the analysis to derive the weighted mean change of $\mathrm{BMI}$ and $\mathrm{AHI}$. AHI, apnoea-hypopnoea index; BMI, body mass index; BPD, biliopancreatic diversion; CPAP, continuous positive airway pressure; DS, duodenal switch; HG, horizontal gastroplasty; NS, not specified; RYGB, Roux-en-Y gastric bypass; SG, sleeve gastrectomy; VBG, vertical banded gastroplasty. 
Table 2 Non-surgical studies of weight loss and indices of sleep apnoea before and after weight loss intervention

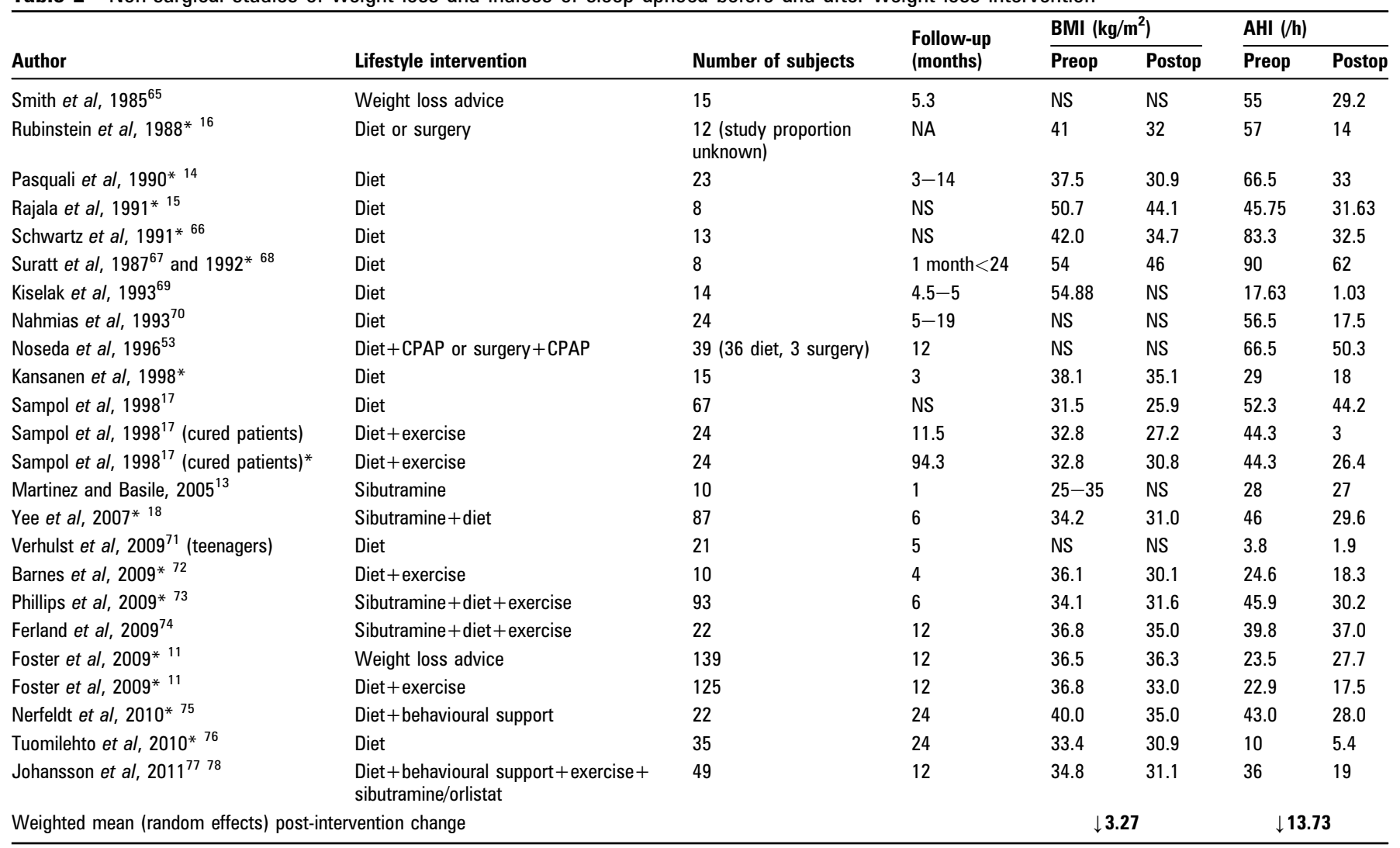

${ }^{*}$ Studies reporting the post-intervention changes of both $\mathrm{BMI}$ and $\mathrm{AHI}$ which were subsequently included in the analysis to derive the weighted mean change of $\mathrm{BMI}$ and $\mathrm{AHI}$. AHI, apnoea-hypopnoea index; BMI, body mass index; CPAP, continuous positive airway pressure; NS, not specified.

variable follow-up times, variable operative procedures and an inconsistency in measuring surgical outcomes. These studies were not intentionally designed to identify sleep apnoea outcomes prospectively and do not fulfil all the criteria for the causal association between metabolic surgery and its effects on sleep apnoea resolution, progression or prevention. Much of the data used may be influenced by the bias of measuring BMI (as patient selection based only on BMI may not reveal the full effect of surgery on OSA), ascertainment bias (sampling from non-random cohorts), treatment biases (such as those for continuous positive airway pressures), intervention bias (such as otolaryngology intervention) and differential follow-up bias (comparing results from patients with variable follow-up times).

Nevertheless, these studies suggest an association between metabolic operations, improved polysomnography results and decreased sleep apnoea symptoms. This may occur through a variety of mechanisms including weight-dependent and weight-independent metabolic pathways.

\section{MECHANISMS OF OSA RESOLUTION AFTER METABOLIC SURGERY}

Metabolic surgery offers a number of protective mechanisms that may lead to decreased symptoms of OSA. Metabolic surgical actions (BRAVE effects) modulate the systemic metabolism to achieve metabolic enhancements and mechanical improvements in disease resolution (figure 1).

\section{Decreased sleep apnoea and weight loss}

Decreased obesity achieved through surgical weight loss may contribute to a reduction or resolution of OSA. The prospective non-randomised controlled SOS study revealed that 10-year surgical weight loss was as high as $25 \%$ for 58 patients who underwent gastric bypass compared with no weight loss (actually a mild weight increase) in the 886 medically-treated patients. ${ }^{5}$ Dixon et al ${ }^{79}$ demonstrated that, at 2 years, laparoscopic adjustable gastric banding surgery achieved $20.7 \%$ weight loss compared with $1.7 \%$ in medically-treated patients in a randomised controlled trial of patients with recently diagnosed type 2 diabetes with a BMI of $30-40 \mathrm{~kg} / \mathrm{m}^{2}$.

The mechanisms for weight loss after metabolic surgery are multifactorial and include alterations in hunger, satiety, food preferences, alterations in metabolic rate, metabolic modulation, the gut microbiome and increased exercise capacity. As a result, the effects of surgery on weight are much broader than the unverified extent of nutrient malabsorption or the mechanical occlusive effect of stomach restriction.

Surgically-induced weight loss may reduce the severity of sleep apnoea through the mechanical decrease of adiposity (both visceral and subcutaneous). As a result, this can alleviate the physical pressure on the neck, upper airway and the breathing apparatus (including the diaphragm which may also receive excess pressure from visceral fat ${ }^{80}$ in addition to beneficial anatomical changes (airway size, collapsibility, changes in functional residual capacity).

There is also some evidence associating obesity with poor or short sleep, ${ }^{81}{ }^{82}$ which might reveal further potential benefits of surgery by reversing this harmful association and improving sleep quality and length. A randomised trial in patients of normal weight showed that short sleep duration $(4 \mathrm{~h})$ resulted in a decrease in the satiety hormone leptin by $18 \%$, an increase in the appetite stimulating hormone ghrelin by $28 \%$ and an overall increase of both appetite and hunger by $23-24 \%$ (associated with 
an increased consumption of calorie-dense foods with high carbohydrate content) when compared to subjects with long sleep duration (10h). ${ }^{82}$ This finding has been supported by several large epidemiological studies associating sleep duration with BMI. 81 The literature, however, is still unclear in differentiating between the metabolic effects of general sleep restriction and the sleep fragmentation of sleep apnoea. As a result, the metabolic contribution of surgery in this context requires further robust evidence.

Comparing the effects of surgical and non-surgical weight loss on sleep apnoea severity can help identify the relative contribution of surgical weight loss on disease resolution. We calculated the weighted mean change (random effects model) of BMI and AHI of all lifestyle intervention and medical studies (diet, exercise, behaviour and drugs including sibutramine) to date using the databases Medline, PubMed, EMBASE and the Cochrane Library (from inception to June 2011) reporting on both BMI and AHI (inclusion criteria for analysis). We found that, in 685 subjects with a mean BMI of $36 \mathrm{~kg} / \mathrm{m}^{2}$, non-surgical weight loss therapies resulted in a weighted decrease in BMI of $3.27 \mathrm{~kg} / \mathrm{m}^{2}$ (3.27, 95\% CI 2.41 to 4.14$)$ and a weighted decrease in AHI by $13.73 / \mathrm{h} \quad(13.73,95 \%$ CI 8.60 to 18.86$)$ (RevMan Computer program Version 5.0. Copenhagen: The Nordic Cochrane Centre, Cochrane Collaboration, 2008). This statistical pooling analysis was only possible for a limited number of studies because data were lacking.

Weight loss by any means has a beneficial effect on sleep apnoea and AHI (tables 1 and 2), although few studies have directly compared these treatments for robust sleep apnoea endpoints. The finding that some non-surgical weight loss therapies offer significant improvements in AHI with much more modest weight loss than in the surgical studies emphasises the likely contribution of anatomical factors that can modify the severity of sleep apnoea further to the metabolic and weight loss changes noted after surgery. Currently, there are limited choices for weight loss medications and many of the dietary therapies that have a beneficial effect on sleep apnoea are based on a low calorie diet which many individuals cannot tolerate in the long term. Metabolic surgery, however, can provide a longstanding and well-tolerated decrease in caloric intake, although it is associated with the risk of surgical mortality and morbidity in the early postoperative period.

\section{Cytokine and anti-inflammatory effects}

Patients with excessive daytime sleepiness (EDS) and sleep apnoea have increased levels of the proinflammatory cytokines interleukin (IL)- 6 and tumour necrosis factor $\alpha$ (TNF $\alpha){ }^{84}$ Although the plasma levels of these cytokines are also positively associated with BMI, IL-6, TNF, leptin and insulin are elevated in patients with sleep apnoea independent of obesity. The inflammatory biomarker C-reactive protein (CRP) is also elevated in sleep apnoea, and serum CRP levels correlate with polysomnography scores independent of adiposity. ${ }^{85}$

Surgical and non-surgical weight loss can result in a decrease of IL-6 and several other oxidative stress and systemic inflammatory markers including CRP, sialic acid, plasminogen activator inhibitor-1, malondialdehyde and von Willebrand factor; conversely, IL-8 levels can be increased. ${ }^{8}{ }^{65}$ IL- 6 is reported to decrease in two-thirds of studies of this cytokine after metabolic surgery, with levels falling by $9-59 \%$. Analysis by multiple regression has shown that the reduction in postoperative insulin resistance after surgery is independently associated with a decrease in IL-6 concentrations. ${ }^{86}$ TNF $\alpha$ was reduced in one study of patients undergoing liposuction ${ }^{87}$ (which does not offer long-term metabolic or weight loss effects) and was not modulated in patients undergoing metabolic surgery, ${ }^{61}$ although the levels of the soluble TNF- $\alpha$ receptor 2 (sTNF $\alpha \mathrm{R} 2)$ were decreased after bariatric surgery (independent of weight loss and other covariates). ${ }^{65}$ The cytokine effects of metabolic procedures-specifically those on IL-6 (and the TNF- $\alpha /$ IL-6 ratio)-may contribute to disease resolution after surgery, although it is difficult to differentiate between the direct mechanistic contribution of surgical weight loss and cytokine modulation to sleep apnoea.

\section{Type 2 diabetes mellitus and insulin resistance}

There is increasing epidemiological and clinical evidence associating type 2 diabetes mellitus and insulin resistance with OSA. The prevalence of OSA in diabetic men is approximately $23 \%$ compared with $6 \%$ in a community-based cohort. ${ }^{88}$ Furthermore, the prevalence of OSA in obese patients with type 2 diabetes can be as high as $86 \%$ based on polysomnographic criteria.

Several population-based studies have shown that OSA has metabolic features and complications in addition to its mechanical sequelae. This condition is a risk factor for insulin resistance independent of age, gender, BMI and waist circumference. Clinically, patients have higher fasting blood glucose levels and insulin levels compared with age- and BMImatched controls. Even mild sleep apnoea can result in glucose intolerance ${ }^{89}$ and, furthermore, non-obese subjects with sleep apnoea can develop insulin resistance. ${ }^{90}$ Although some studies have not shown a consistent association between sleep apnoea and insulin resistance, this may be affected by the diagnostic accuracy of sleep apnoea and insulin resistance measurements in these cohorts. Possible mechanisms associating sleep apnoea and insulin resistance include the direct effects of obesity and the modulation of the autonomic nervous system on sympathetic drive. ${ }^{91}$ Early reports show that improvements in OSA by continuous positive airway pressure (CPAP) therapy might improve glycaemic control, ${ }^{92}$ but this has not been universally demonstrated $^{93}$ and there is currently no clear evidence that the successful treatment of insulin resistance and diabetes results in improved sleep apnoea symptoms. As a result, the proposed causation between impaired glucose metabolism and OSA still needs to be proven.

Among the most pronounced effects of metabolic surgery is the improvement in glycaemic control and decreased cardiovascular risk (including a reduction in OSA-associated atrial fibrillation). ${ }^{89}$ A recent systematic review and meta-analysis of the effects of metabolic surgery on diabetes incorporating 621 studies with 888 treatment arms and 135246 patients reported that $78.1 \%$ of diabetic patients had a fasting glucose level $<7 \mathrm{mmol} / \mathrm{l}$ and glycaemic control was improved in $86.6 \%$ of patients. $^{7}$

Mechanisms of improved glycaemic control in patients undergoing metabolic surgery include the long-term effects of surgical weight loss in addition to several mechanisms independent of weight loss such as the modulation of the gut hormone glucagon-like peptide- 1 which together improve insulin resistance and improve insulin secretion after surgery. These include the rearrangement of the gastrointestinal anatomy through foregut, midgut and hindgut hypotheses. ${ }^{9} 469495$ Metabolic procedures also offer the beneficial modulation of the autonomic nervous system which may contribute to the resolution of diabetes, sleep apnoea and even obesity-associated heart rate dysrhythmias in morbidly obese subjects. 89697 The improvement in insulin resistance resulting from these metabolic surgical 
procedures may therefore contribute to the improvements and resolution of OSA observed in these operations.

\section{Adipokines}

Leptin is a $16 \mathrm{kDa}$ product of the adipose obese (ob) gene, mainly synthesised by fat cells. It acts on the hypothalamus to increase energy expenditure and decrease food intake. In nonobese individuals, raised leptin levels result in the expected rise in energy expenditure and decreased food intake. In obese individuals, however, circulating levels are chronically high without a significant decrease on food intake or increased energy expenditure, which suggests that there is leptin insensitivity in the obese state. Hyperleptinaemia is associated with obesity hypoventilation and sleep apnoea and metabolic procedures decrease serum leptin levels in proportion to postoperative weight loss. ${ }^{98}$

\section{Gut hormones and sex steroids}

Obese patients with sleep apnoea have increased levels of the orexigenic (appetite stimulating) hormone ghrelin, the levels being positively correlated with the number of sleep-disordered breathing events. ${ }^{99} 100$ Both adenotonsillectomy in children with sleep-disordered breathing and nasal CPAP in adults can decrease ghrelin levels. ${ }^{100} 101$ The effects of metabolic surgery on the modulation of ghrelin is controversial in view of the large variation in ghrelin levels reported postoperatively. ${ }^{94}$ As a result, it has been difficult to determine whether the surgical modulation of ghrelin results from weight-independent surgical effects (as is the case for glucagon-like peptide-1 or peptide YY) or those secondary to surgical weight loss. Further investigation to clarify the role of metabolic surgery on gut hormones and sleep apnoea may offer novel treatments and an increased understanding of the disease mechanism.

The current evidence associating sleep apnoea and sex steroids identifies the role of a decrease in menopausal hormone in sleep apnoea and the possible therapeutic role of oestrogen and progesterone replacement therapy. ${ }^{40-42}$ The studies to date have not, however, identified the role of these sex hormones on sleep apnoea in the context of obesity. Metabolic surgery is known to have beneficial effects on sex steroid-related physiology including improved fertility, polycystic ovary syndrome and libido, mainly attributed to weight loss effects. ${ }^{102}$ The surgical modulation of sex steroids may contribute to the observed postoperative decrease in obesity-related female cancers ${ }^{103}$ and are considered to occur predominantly through weight loss effects. These procedures decrease the levels of oestradiol and sex hormone-binding globulin, although the effect of these changes requires formal study in the context of sleep apnoea.

\section{CONCLUSIONS}

Metabolic surgery is increasingly being performed worldwide as the obesity epidemic advances. As these procedures induce significant metabolic changes, they are no longer applied with the sole purpose of weight loss but are progressively being used to improve patient health and are now considered to produce 'bionic' effects. ${ }^{104}$ Metabolic surgery offers a significant reduction of the symptoms and measures of OSA. The beneficial effects of metabolic surgery on OSA may include both weightdependent and weight-independent mechanisms. These include adipokine effects, cytokine actions, altered gut hormonal release and the improvement of insulin resistance. Identifying the precise mechanisms through which metabolic surgery improves or resolves OSA will increase our understanding of how obesity and metabolic dysfunction contribute to this multisystem sleep disorder. Currently, the heterogeneity across the available trials and a deficiency in comparative studies between surgical and non-surgical therapy precludes definitive statements regarding the relative benefits of surgical therapy.

The future of this field requires further research to outline robustly the mechanisms and translational clinical effects of sleep apnoea resolution after metabolic surgery. This includes the quantification of weight-dependent and weight-independent effects on disease resolution and will require further randomised control trials of both in vitro and in vivo (animal) models of metabolic surgery and sleep-disordered breathing. Furthermore, mechanistic studies can employ genomic, transcriptomic and metabolic profiles using a systems biology approach. ${ }^{105}$ This may ultimately offer a refinement of metabolic procedures to maximise their effects on OSA. It may also offer novel treatment strategies in the management of sleep-disordered breathing.

Acknowledgements We are grateful for support from the Wellcome Trust and the NIHR Biomedical Research Centre Funding Scheme. We acknowledge Dr Kari Johansson, Dr Gary Foster, Dr Kelley Borradaile, Professor Alan R Schwartz, Dr Maria Pallayova, Professor Hannu Tukiainen and Dr Henri Tuomilehto who provided supplementary data for statistical analysis.

Funding Wellcome Trust.

Provenance and peer review Not commissioned; externally peer reviewed.

\section{REFERENCES}

1. World Health Organization. Obesity and Overweight - Fact Sheet N³11. 2006 http://www.who.int/mediacentre/factsheets/fs311/en/index.html.

2. World Health Organization. Global Surveillance, Prevention and Control of Chronic Respiratory Diseases: A Comprehensive Approach. Geneva: World Health Organization, 2007.

3. Young T, Peppard PE, Gottlieb DJ. Epidemiology of obstructive sleep apnea: a population health perspective. Am J Respir Crit Care Med 2002;165:1217-39.

4. Sjostrom L, Lindroos AK, Peltonen M, et al. Lifestyle, diabetes, and cardiovascula risk factors 10 years after bariatric surgery. N Engl J Med 2004;351:2683-93.

5. Sjostrom L, Narbro K, Sjostrom CD, et al. Effects of bariatric surgery on mortality in Swedish obese subjects. N Engl J Med 2007;357:741-52.

6. Buchwald $\mathbf{H}$, Avidor $Y$, Braunwald $E$, et al. Bariatric surgery: a systematic review and meta-analysis. JAMA 2004;292:1724-37.

7. Buchwald H, Estok R, Fahrbach K, et al. Weight and type 2 diabetes after bariatric surgery: systematic review and meta-analysis. Am J Med 2009;122:248-56.e5.

8. Ashrafian H, le Roux CW, Darzi A, et al. Effects of bariatric surgery on cardiovascular function. Circulation 2008;118:2091-102.

9. Ashrafian H, Athanasiou T, Li JV, et al. Diabetes resolution and hyperinsulinaemia after metabolic Roux-en-Y gastric bypass. Obes Rev. [Epub ahead of print] 2010 Sep 29. doi:10.1111/j.1467-789X.2010.00802.x.

10. Young T, Palta M, Dempsey J, et al. The occurrence of sleep-disordered breathing among middle-aged adults. N Engl J Med 1993;328:1230-5.

11. Foster GD, Borradaile KE, Sanders MH, et al. A randomized study on the effect of weight loss on obstructive sleep apnea among obese patients with type 2 diabetes: the Sleep AHEAD study. Arch Intern Med 2009;169:1619-26.

12. Foster GD, Sanders MH, Millman R, et al. Obstructive sleep apnea among obese patients with type 2 diabetes. Diabetes Care 2009;32:1017-19.

13. Martinez D, Basile BR. Sibutramine does not worsen sleep apnea syndrome: a randomized double-blind placebo-controlled study. Sleep Med 2005;6:467-70.

14. Pasquali R, Colella P, Cirignotta F, et al. Treatment of obese patients with obstructive sleep apnea syndrome (OSAS): effect of weight loss and interference of otorhinolaryngoiatric pathology. Int J Obes 1990;14:207-17.

15. Rajala R, Partinen M, Sane T, et al. Obstructive sleep apnoea syndrome in morbidly obese patients. J Intern Med 1991;230:125-9.

16. Rubinstein I, Colapinto N, Rotstein LE, et al. Improvement in upper airway function after weight loss in patients with obstructive sleep apnea. Am Rev Respir Dis 1988;138:1192-5

17. Sampol G, Munoz X, Sagales MT, et al. Long-term efficacy of dietary weight loss in sleep apnoea/hypopnoea syndrome. Eur Respir J 1998;12:1156-9.

18. Yee BJ, Phillips CL, Banerjee D, et al. The effect of sibutramine-assisted weight loss in men with obstructive sleep apnoea. Int J Obes (Lond) 2007;31:161-8.

19. Ashrafian H. Familial proptosis and obesity in the Ptolemies. J R Soc Med 2005:98:85-6.

20. Michalopoulos A, Tzelepis G, Geroulanos S. Morbid obesity and hypersomnolence in several members of an ancient royal family. Thorax 2003:58:281-2.

21. Vgontzas AN, Tan TL, Bixler E0, et al. Sleep apnea and sleep disruption in obese patients. Arch Intern Med 1994;154:1705-11.

22. Hiestand DM, Britz P, Goldman M, et al. Prevalence of symptoms and risk of sleep apnea in the US population: results from the national sleep foundation sleep in America 2005 poll. Chest 2006;130:780-6. 
23. Peiser $\mathbf{J}$, Lavie $\mathrm{P}$, Ovnat A, et al. Sleep apnea syndrome in the morbidly obese as an indication for weight reduction surgery. Ann Surg 1984;199:112-15

24. Charuzi I, Fraser D, Peiser J, et al. Sleep apnea syndrome in the morbidly obese undergoing bariatric surgery. Gastroenterol Clin North Am 1987:16:517-19.

25. Charuzi I, Lavie P, Peiser J, et al. Bariatric surgery in morbidly obese sleep-apnea patients: short- and long-term follow-up. Am J Clin Nutr 1992:55:594S-6S.

26. Charuzi I, Ovnat A, Peiser J, et al. The effect of surgical weight reduction on sleep quality in obesity-related sleep apnea syndrome. Surgery 1985;97:535-8.

27. Dixon JB, Schachter LM, O'Brien PE. Polysomnography before and after weight loss in obese patients with severe sleep apnea. Int J Obes (Lond) 2005;29:1048-54.

28. Haines KL, Nelson LG, Gonzalez R, et al. Objective evidence that bariatric surgery improves obesity-related obstructive sleep apnea. Surgery 2007:141:354-8.

29. Harman EM, Wynne JW, Block AJ. The effect of weight loss on sleep-disordered breathing and oxygen desaturation in morbidly obese men. Chest 1982;82:291-4.

30. Lettieri CJ, Eliasson AH, Greenburg DL. Persistence of obstructive sleep apnea after surgical weight loss. J Clin Sleep Med 2008:4:333-8.

31. Marti-Valeri C, Sabate A, Masdevall C, et al. Improvement of associated respiratory problems in morbidly obese patients after open Roux-en-Y gastric bypass. Obes Surg 2007:17:1102-10.

32. Pillar G, Peled R, Lavie P. Recurrence of sleep apnea without concomitant weight increase 7.5 years after weight reduction surgery. Chest 1994;106:1702-4.

33. Rao A, Tey BH, Ramalingam G, et al. Obstructive sleep apnoea (OSA) patterns in bariatric surgical practice and response of OSA to weight loss after laparoscopic adjustable gastric banding (LAGB). Ann Acad Med Singapore 2009;38:587-93.

34. Sugerman HJ, Fairman RP, Sood RK, et al. Long-term effects of gastric surgery for treating respiratory insufficiency of obesity. Am J Clin Nutr 1992;55:597S-601S.

35. Valencia-Flores $\mathbf{M}$, Orea A, Herrera M, et al. Effect of bariatric surgery on obstructive sleep apnea and hypopnea syndrome, electrocardiogram, and pulmonary arterial pressure. Obes Surg 2004;14:755-62.

36. Young T, Shahar E, Nieto FJ, et al. Predictors of sleep-disordered breathing in community-dwelling adults: the Sleep Heart Health Study. Arch Intern Med 2002;162:893-900

37. Tishler PV, Larkin EK, Schluchter MD, et al. Incidence of sleep-disordered breathing in an urban adult population: the relative importance of risk factors in the development of sleep-disordered breathing. JAMA 2003;289:2230-7.

38. Lopez PP, Stefan B, Schulman $\mathrm{Cl}$, et al. Prevalence of sleep apnea in morbidly obese patients who presented for weight loss surgery evaluation: more evidence for routine screening for obstructive sleep apnea before weight loss surgery. Am Surg 2008; 74:834-8.

39. Santiago-Recuerda A, Gomez-Terreros FJ, Caballero P, et al. Relationship between the upper airway and obstructive sleep apnea-hypopnea syndrome in morbidly obese women. Obes Surg 2007:17:689-97.

40. Behan M, Wenninger JM. Sex steroidal hormones and respiratory control. Respir Physiol Neurobiol 2008;164:213-21.

41. Shahar E, Redline S, Young T, et al. Hormone replacement therapy and sleep-disordered breathing. Am J Respir Crit Care Med 2003;167:1186-92.

42. Young T, Finn L, Austin D, et al. Menopausal status and sleep-disordered breathing in the Wisconsin Sleep Cohort Study. Am J Respir Crit Care Med 2003;167:1181-5.

43. Bixler E0, Vgontzas AN, Ten Have T, et al. Effects of age on sleep apnea in men: I. Prevalence and severity. Am J Respir Crit Care Med 1998;157:144-8.

44. Dixon JB, Schachter LM, O'Brien PE. Predicting sleep apnea and excessive day sleepiness in the severely obese: indicators for polysomnography. Chest 2003;123:1134-41

45. Buchwald H, Oien DM. Metabolic/bariatric surgery worldwide 2008. Obes Surg 2009:19:1605-11.

46. Ashrafian H, Bueter M, Ahmed K, et al. Metabolic surgery: an evolution through bariatric animal models. Obes Rev 2010;11:907-20.

47. Flum DR, Belle SH, King WC, et al. Perioperative safety in the longitudinal assessment of bariatric surgery. N Engl J Med 2009;361:445-54.

48. Ashrafian H, Darzi A, Athanasiou A. Bariatric surgery: can we afford to do it or deny doing it? Frontline Gastroenterol 2011;2:82-9.

49. Adams TD, Gress RE, Smith SC, et al. Long-term mortality after gastric bypass surgery. N Engl J Med 2007;357:753-61.

50. Grunstein RR, Stenlof K, Hedner JA, et al. Two year reduction in sleep apnea symptoms and associated diabetes incidence after weight loss in severe obesity. Sleep 2007;30:703-10.

51. Greenburg DL, Lettieri CJ, Eliasson AH. Effects of surgical weight loss on measures of obstructive sleep apnea: a meta-analysis. Am J Med 2009;122:535-42.

52. Summers CL, Stradling JR, Baddeley RM. Treatment of sleep apnoea by vertical gastroplasty. Br J Surg 1990:77:1271-2.

53. Noseda A, Kempenaers C, Kerkhofs M, et al. Sleep apnea after 1 year domiciliary nasal-continuous positive airway pressure and attempted weight reduction. Potential for weaning from continuous positive airway pressure. Chest 1996; 109:138-43.

54. Scheuller $\mathbf{M}$, Weider D. Bariatric surgery for treatment of sleep apnea syndrome in 15 morbidly obese patients: long-term results. Otolaryngol Head Neck Surg 2001; 125:299-302

55. Rasheid S, Banasiak M, Gallagher SF, et al. Gastric bypass is an effective treatment for obstructive sleep apnea in patients with clinically significant obesity. Obes Surg 2003;13:58-61.
56. Guardiano SA, Scott JA, Ware JC, et al. The long-term results of gastric bypass on indexes of sleep apnea. Chest 2003;124:1615-19.

57. Busetto L, Enzi G, Inelmen EM, et al. Obstructive sleep apnea syndrome in morbid obesity: effects of intragastric balloon. Chest 2005;128:618-23.

58. Lankford DA, Proctor CD, Richard R. Continuous positive airway pressure (CPAP) changes in bariatric surgery patients undergoing rapid weight loss. Obes Surg 2005; 15:336-41.

59. Kalra M, Inge T, Garcia V, et al. Obstructive sleep apnea in extremely overweight adolescents undergoing bariatric surgery. Obes Res 2005:13:1175-9.

60. Poitou C, Coupaye M, Laaban JP, et al. Serum amyloid A and obstructive sleep apnea syndrome before and after surgically-induced weight loss in morbidly obese subjects. Obes Surg 2006:16:1475-81.

61. Fritscher LG, Canani S, Mottin CC, et al. Bariatric surgery in the treatment of obstructive sleep apnea in morbidly obese patients. Respiration 2007:74:647-52.

62. Varela JE, Hinojosa MW, Nguyen NT. Resolution of obstructive sleep apnea after laparoscopic gastric bypass. Obes Surg 2007;17:1279-82.

63. Kuzniar TJ, Morgenthaler TI. A patient with obstructive sleep apnea undergoing bariatric surgery. J Clin Sleep Med 2008;4:279-80.

64. Pallayova M, Steele KE, Magnuson TH, et al. Sleep Apnea Determines Soluble TNF- $\alpha$. Receptor 2 Response to Massive Weight Loss. Obes Surg. 2011 Feb 6. [Epub ahead of print] PubMed PMID: 21298510

65. Smith PL, Gold AR, Meyers DA, et al. Weight loss in mildly to moderately obese patients with obstructive sleep apnea. Ann Intern Med 1985:103:850-5

66. Schwartz AR, Gold AR, Schubert N, et al. Effect of weight loss on upper airway collapsibility in obstructive sleep apnea. Am Rev Respir Dis 1991;144:494-8.

67. Suratt PM, McTier RF, Findley LJ, et al. Changes in breathing and the pharynx after weight loss in obstructive sleep apnea. Chest 1987;92:631-7.

68. Suratt PM, McTier RF, Findley LJ, et al. Effect of very-low-calorie diets with weight loss on obstructive sleep apnea. Am J Clin Nutr 1992;56:182S-4S.

69. Kiselak J, Clark M, Pera V, et al. The association between hypertension and sleep apnea in obese patients. Chest 1993:104:775-80.

70. Nahmias J, Kirschner M, Karetzky MS. Weight loss and OSA and pulmonary function in obesity. N J Med 1993;90:48-53.

71. Verhulst SL, Franckx H, Van Gaal L, et al. The effect of weight loss on sleep-disordered breathing in obese teenagers. Obesity (Silver Spring) 2009;17:1178-83.

72. Barnes M, Goldsworthy UR, Cary BA, et al. A diet and exercise program to improve clinical outcomes in patients with obstructive sleep apnea - a feasibility study. $J$ Clin Sleep Med 2009:5:409-15.

73. Phillips CL, Yee BJ, Trenell Ml, et al. Changes in regional adiposity and cardiometabolic function following a weight loss program with sibutramine in obese men with obstructive sleep apnea. J Clin Sleep Med 2009:5:416-21.

74. Ferland A, Poirier P, Series F. Sibutramine versus continuous positive airway pressure in obese obstructive sleep apnoea patients. Eur Respir $J$ 2009:34:694-701.

75. Nerfeldt $\mathbf{P}$, Nilsson BY, Mayor L, et al. A two-year weight reduction program in obese sleep apnea patients. J Clin Sleep Med 2010;6:479-86.

76. Tuomilehto $\mathbf{H}$, Gylling $\mathbf{H}$, Peltonen $\mathbf{M}$, et al. Sustained improvement in mild obstructive sleep apnea after a diet- and physical activity-based lifestyle intervention: postinterventional follow-up. Am J Clin Nutr 2010:92:688-96.

77. Johansson K, Neovius M, Lagerros YT, et al. Effect of a very low energy diet on moderate and severe obstructive sleep apnoea in obese men: a randomised controlled trial. BMJ 2009;339:b4609.

78. Johansson $\mathbf{K}$, Hemmingsson $\mathrm{E}$, Harlid $\mathrm{R}$, et al. Longer term effects of very low energy diet on obstructive sleep apnoea in cohort derived from randomised controlled trial: prospective observational follow-up study. BMJ 2011;342:d3017.

79. Dixon JB, O'Brien PE, Playfair J, et al. Adjustable gastric banding and conventional therapy for type 2 diabetes: a randomized controlled trial. JAMA 2008;299:316-23

80. Simpson L, Mukherjee S, Cooper MN, et al. Sex differences in the association of regional fat distribution with the severity of obstructive sleep apnea. Sleep 2010;33:467-74

81. Spiegel K, Tasali E, Leproult R, et al. Effects of poor and short sleep on glucose metabolism and obesity risk. Nat Rev Endocrinol 2009:5:253-61.

82. Spiegel K, Tasali E, Penev P, et al. Brief communication: sleep curtailment in healthy young men is associated with decreased leptin levels, elevated ghrelin levels, and increased hunger and appetite. Ann Intern Med 2004;141:846-50.

83. Patel SR, Blackwell T, Redline $\mathrm{S}$, et al. The association between sleep duration and obesity in older adults. Int J Obes (Lond) 2008:32:1825-34.

84. Vgontzas AN, Papanicolaou DA, Bixler EO, et al. Elevation of plasma cytokines in disorders of excessive daytime sleepiness: role of sleep disturbance and obesity. $J$ Clin Endocrinol Metab 1997:82:1313-16.

85. Punjabi NM, Beamer BA. C-reactive protein is associated with sleep disordered breathing independent of adiposity. Sleep 2007:30:29-34.

86. Kopp HP, Kopp CW, Festa A, et al. Impact of weight loss on inflammatory proteins and their association with the insulin resistance syndrome in morbidly obese patients. Arterioscler Thromb Vasc Biol 2003:23:1042-7.

87. Giugliano G, Nicoletti G, Grella E, et al. Effect of liposuction on insulin resistance and vascular inflammatory markers in obese women. Br J Plast Surg 2004:57:190-4

88. West SD, Nicoll DJ, Stradling JR. Prevalence of obstructive sleep apnoea in men with type 2 diabetes. Thorax 2006;61:945-50. 
89. Punjabi NM, Sorkin JD, Katzel LI, et al. Sleep-disordered breathing and insulin resistance in middle-aged and overweight men. Am J Respir Crit Care Med 2002;165:677-82.

90. Ip MS, Lam B, Ng MM, et al. Obstructive sleep apnea is independently associated with insulin resistance. Am J Respir Crit Care Med 2002;165:670-6.

91. Narkiewicz K, Somers VK. Sympathetic nerve activity in obstructive sleep apnoea. Acta Physiol Scand 2003;177:385-90.

92. Steiropoulos $\mathbf{P}$, Papanas N, Nena E, et al. Continuous positive airway pressure treatment in patients with sleep apnoea: does it really improve glucose metabolism? Curr Diabetes Rev 2010;6:156-66.

93. West SD, Nicoll DJ, Wallace TM, et al. Effect of CPAP on insulin resistance and $\mathrm{HbA} 1 \mathrm{C}$ in men with obstructive sleep apnoea and type 2 diabetes. Thorax 2007;62:969-74.

94. Ashrafian H, le Roux CW. Metabolic surgery and gut hormones-a review of bariatric entero-humoral modulation. Physiol Behav 2009;97:620-31.

95. Vincent RP, Ashrafian H, le Roux CW. Mechanisms of disease: the role of gastrointestinal hormones in appetite and obesity. Nat Clin Pract Gastroenterol Hepatol 2008;5:268-77.

96. Wasmund SL, Owan T, Yanowitz FG, et al. Improved heart rate recovery after marked weight loss induced by gastric bypass surgery: two-year follow-up in the Utah Obesity Study. Heart Rhythm 2011;8:84-90.
97. Ashrafian $\mathbf{H}$, Athanasiou T, le Roux CW et al. Heart remodelling and obesity: the complexities and variation of cardiac geometry. Heart. 2011 Feb;97(3):171-2.

98. Nijhuis J, van Dielen FM, Buurman WA, et al. Ghrelin, leptin and insulin levels after restrictive surgery: a 2-year follow-up study. Obes Surg 2004:14:783-7.

99. Spruyt K, Sans Capdevila 0, Serpero LD, et al. Dietary and physical activity patterns in children with obstructive sleep apnea. J Pediatr 2010;156:724-30.

100. Takahashi K, Chin K, Akamizu T, et al. Acylated ghrelin level in patients with OSA before and after nasal CPAP treatment. Respirology 2008;13:810-16.

101. Gumussoy M, Atmaca S, Bilgici B et al. Changes in IGF-I, IGFBP-3 and ghrelin levels after adenotonsillectomy in children with sleep disordered breathing. Int J Pediatr Otorhinolaryngol 2009;73:1653-6.

102. Scholtz S, Le Roux C, Balen AH. The role of bariatric surgery in the management of female fertility. Hum Fertil (Camb) 2010;13:67-71.

103. Ashrafian H, Ahmed K, Rowland SP, et al. Metabolic surgery and cancer: protective effects of bariatric procedures. Cancer. 2010 Nov 29. [Epub ahead of print] PubMed PMID: 21117217.

104. Ashrafian H, Darzi A, Athanasiou T. Autobionics: a new paradigm in regenerative medicine and surgery. Regen Med 2010;5:279-88.

105. Li JV, Ashrafian H, Bueter M, et al. Metabolic surgery profoundly influences gut microbial-host metabolic cross-talk. Gut. Published Online First 14 May 2011. doi:10.1136/gut.2010.234708

Advancing Postgraduates. Enhancing Healthcare.

The Postgraduate Medical Journal is dedicated to advancing the understanding of postgraduate medical education and training.

- Acquire the necessary skills to deliver the highest possible standards of patient care

- Develop suitable training programmes for your trainees

- Maintain high standards after training ends

Published on behalf of the fellowship for Postgraduate Medicine

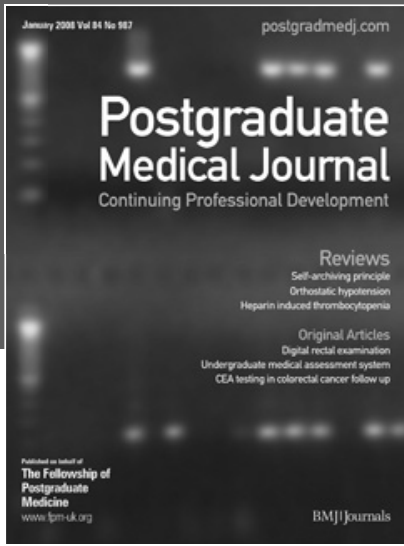

FOR MORE DETAILS OR TO SUBSCRIBE,

VISIT THE WEBSITE TODAY

BMJIJournals

postgradmedj.com 